\title{
Sexual Intercourse and Its Correlates Among School-aged Adolescents in Indonesia: Analysis of the 2015 Global School-based Health Survey
}

\author{
Anissa Rizkianti ${ }^{1}$, Iram Barida Maisya ${ }^{1}$, Nunik Kusumawardani ${ }^{1}$, Christine Linhart ${ }^{2}$, Jerico Franciscus Pardosi ${ }^{1,3}$ \\ ${ }^{1}$ Centre for Research and Development of Public Health Efforts, National Institute of Health Research and Development (NIHRD), Jakarta, \\ Indonesia; ${ }^{2}$ School of Public Health and Community Medicine, Faculty of Medicine, University of New South Wales, Sydney, Australia; ${ }^{3}$ School of \\ Public Health and Social Work, Faculty of Health, Queensland University of Technology, Brisbane, Australia
}

Objectives: This study aimed to determine the prevalence and correlates of sexual intercourse among junior secondary and high school students in Indonesia from the 2015 Global School-based Health Survey (GSHS).

Methods: The survey was conducted among 11110 students from 75 schools in Indonesia using a self-administered questionnaire. Univariate and multivariate analyses were conducted to explore associations between sexual intercourse and socio-demographic variables, substance use, mental distress, and protective factors.

Results: Overall, $5.3 \%$ of students reported having ever had sex (6.9\% of boys and $3.8 \%$ of girls). Of students who engaged in sexual intercourse, $72.7 \%$ of boys and $90.3 \%$ of girls had an early sexual debut (before reaching the age of 15 ) and around $60 \%$ had multiple sex partners. Sexual intercourse was associated with gender, school grade, smoking, alcohol consumption, drug use, suicidal ideation, truancy, peer support, and parental supervision.

Conclusions: These findings indicate a pressing need to develop more comprehensive sexual health education in the national curriculum. An effective strategy should also address other risky behaviours.

Key words: Sexual behaviour, Adolescent, Sexual intercourse, Students, Global School-based Health Survey, Indonesia

\section{INTRODUCTION}

Adolescence is a critical period in an individual's transition in health, social development, and well-being from childhood to adulthood. Adolescents make up $16 \%$ of the world's popula-

Received: February 3, 2020 Accepted: June 11, 2020

Corresponding author: Anissa Rizkianti, MIPH

Centre for Research and Development of Public Health Efforts, National Institute of Health Research and Development (NIHRD), Jakarta 10560, Indonesia

E-mail: anissa.rizkianti@kemkes.go.id

This is an Open Access article distributed under the terms of the Creative Commons Attribution Non-Commercial License (https://creativecommons.org/licenses/by$\mathrm{nc} / 4.0 /$ ) which permits unrestricted non-commercial use, distribution, and reproduction in any medium, provided the original work is properly cited. tion, and Asia is home to more than 600 million adolescents [1]. In 2016, Indonesia had 46 million adolescents, representing $18 \%$ of its total population [2]. As they cope with a range of health and social challenges as they navigate the pathway from childhood to adulthood, it is of the utmost importance for society to invest in them and to help them to thrive. Adolescents are also characterised by heightened impulsivity, which may lead to risky behaviour [3], such as early sexual intercourse. Adolescents often experience premarital sexual activity, which is significantly influenced by biological, psychological, and social factors [4]. Premarital sex is considered socially and culturally taboo in Indonesia. However, data from the 2017 Indonesia Demographic and Health Surveys indicated that around 4\% of man adolescents aged 15-19 had sexual 
experience [5].

Premarital sexual activity among teenagers is mostly unsafe (i.e., without use of a condom), exposing them to various health problems, such as unwanted pregnancy, unsafe abortion, sexually transmitted diseases, and HIV/AIDS [4]. Furthermore, in Indonesia, limited access to targeted sexual and reproductive health (SRH) care and services for adolescents contributes to the high burden of SRH problems [6]. Between 2011 and 2015, new human immunodeficiency virus (HIV) infections in Indonesia increased annually by $13.1 \%$ among adolescents aged 15 to 19 [7]. In addition, approximately $8 \%$ of adolescents aged $\leq 19$ years had experienced an unwanted pregnancy [8].

Early initiation of adolescent sexual intercourse might be influenced by several factors. These include socio-demographic factors, such as men gender [9-11] and older age [9,12], substance use (tobacco, alcohol and drugs) [9-12], depressive symptoms (sadness, loneliness, and anxiety) [9], and truancy $[9,10]$. Furthermore, protective factors, such as positive attitudes from friends [9] and frequent parental supervision [9-11], were found to be associated with lower engagement in sexual activity.

Although many scholars have studied the determinants of sexual intercourse among adolescents, limited information is available on the correlates of sexual intercourse among in-school adolescents in Indonesia. Previous studies have examined correlates of sexual behaviour in Indonesia, including self-esteem, psychological well-being, and social support [13,14]; however, these studies have been limited to few provinces (Jambi, Lampung, Jakarta, and Bali), and the appropriateness of this evidence to guide formulation of SRH policy and curriculum throughout Indonesia is implausible. Therefore, the findings of this study may help develop the most appropriate sexual health program and education for adolescents in Indonesia by using data from the 2015 Indonesia Global School-based Health Survey (GSHS).

\section{METHODS}

\section{Study Design}

This study was based on a secondary analysis of the Indonesia GSHS conducted in 2015. The Indonesia GSHS used a twostage cluster sampling design to generate a representative sample of junior secondary (grade 7-9) and high school students (grade 10-12), who are typically aged 13-17 years. It is a part of collaborative survey between the US Centres for Disease Control (CDC), the World Health Organization, and the Ministry of Health of the Republic of Indonesia.

\section{Sampling and Data Collection Procedure}

At the first stage, the CDC selected a number of schools with probability proportional to school enrolment size. Seventyfive schools were selected from 68 districts in 26 provinces in Indonesia. At the next stage of sampling, classes in the selected schools were randomly selected and all students in the selected classes were eligible to participate irrespective of their actual age. The school response rate was $100 \%$, while the student response rate was $94 \%$. A total of 11110 students participated in this study.

Data collection was taken place in selected schools under supervision of teachers and the research team. Students who did not attend school, were ill, or had difficulties responding to the questionnaire were excluded from the study. The participating students completed a self-administered GSHS standardised questionnaire that took on average 40 minutes to 50 minutes to complete on a computer-scannable answer sheet. They were also asked not to include their name or other identification code. The questionnaires were initially translated into Bahasa Indonesia prior to the study. At least $10 \mathrm{GSHS}$ core questionnaire modules were used to collect demographic information from students, in addition to information on alcohol, tobacco, and drug use; sexual behaviours related to HIV/ AIDS; physical activity; violence/physical abuse; diet and nutrition; hygiene practices; truancy; perceived social support at school; and parental monitoring.

\section{Study Variables}

The variables used in this study are described in Table 1. The dependent variables were sexual intercourse, and the independent variables were socio-demographic characteristics (age, gender, grade), substance use (alcohol, tobacco, and drug use), mental distress (loneliness, anxiety, suicide), truan$c y$, and protective factors (peer support and parental or guardian supervision).

\section{Statistical Analysis}

The data were coded and analysed using SAS Studio (SAS Institute Inc., Cary, NC, USA). The study adopted two ways of analysing of the data. At first, the proportions of sexual behaviour, socio-demographic characteristics, substance use, mental distress, and other protective factors were evaluated according to gender. Missing data were not estimated. Factors associated with sexual intercourse were also assessed using the Pearson chi-square test in the bivariate analysis. Any potential 


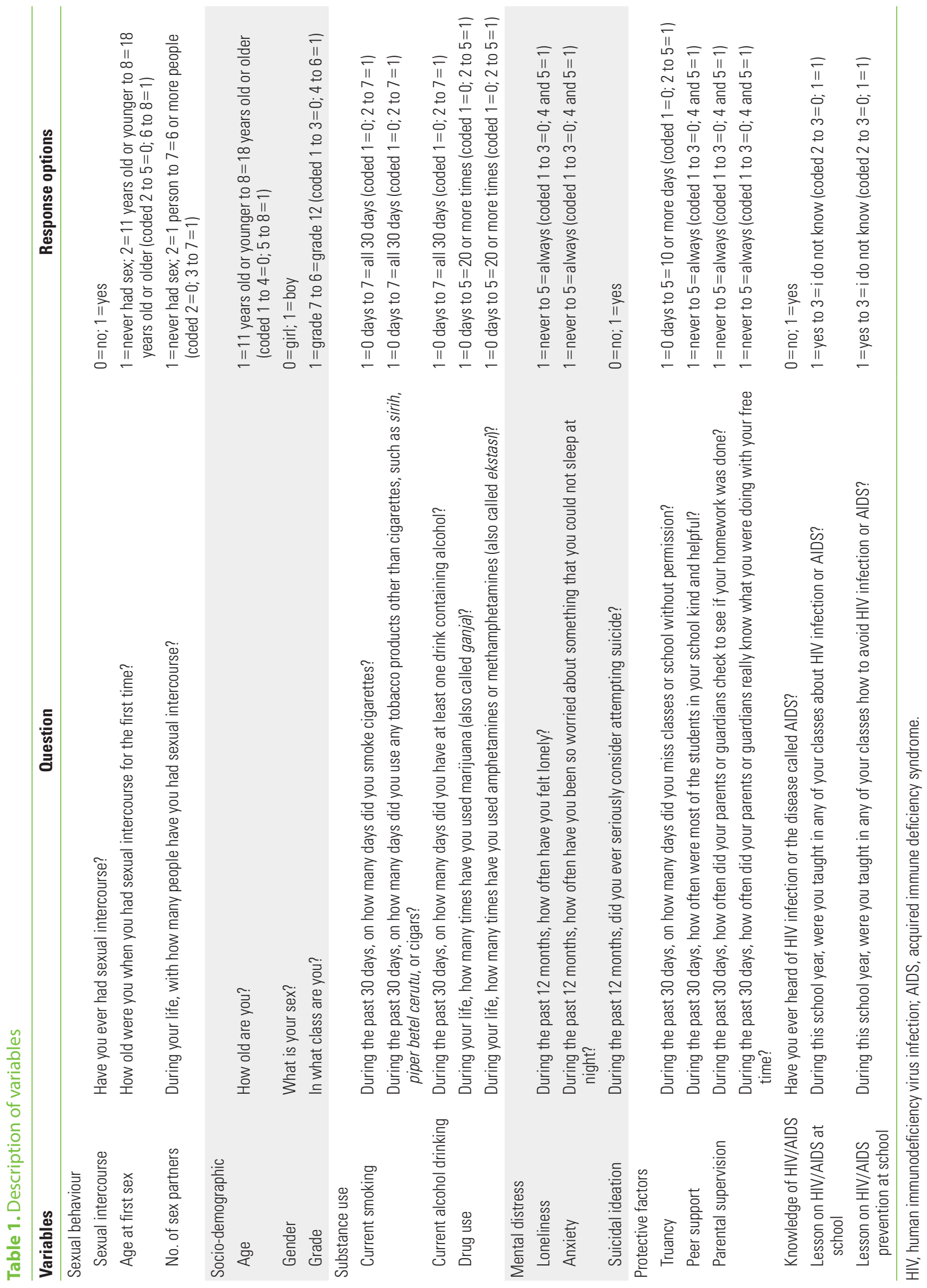


confounders and explanatory variables that were significant at the 0.25 level based on the Wald test were retained and entered into multivariate logistic regression models in the second step. In this step, the backward elimination method was used. The results from the regression analysis were presented as odds ratios (ORs) and adjusted ORs with their respective 95\% confidence intervals (Cls). Sample weights were used to adjust for differences in the probability of selection between students.

\section{Ethics Statement}

The National Ethics Commission on Health Research, National Institute of Health Research and Development granted ethical approval for the 2015 Indonesia GSHS (LB.02.01/5.2/ KE.158/2015). Students were permitted to withdraw from the study at any time before or during data collection and could refuse to answer any questions. To maintain confidentiality, no personal identifiers were provided in the questionnaire and answer sheet.

\section{RESULTS}

\section{Sample Characteristics}

Table 2 presents the sample characteristics. Of the 11110 participants included in the study, $54.2 \%$ were girls and $45.8 \%$ were boys. The majority of participants were junior secondary school students between grades 7 and 9 (76.8\%) and around the age of $10-14$ years (67.7\%). Substance use was greater among boys than girls. The prevalence of current smoking and consumption of other tobacco products was $23.2 \%$ and $2.4 \%$, respectively. The prevalence of current alcohol consumption was $7.3 \%$ among boys and $1.6 \%$ among girls, and that of lifetime illicit drug use was 3.3\% among boys and $0.9 \%$ among girls, whilst mental distress was more likely to occur among girls than boys.

\section{Sexual Behaviour and Associated Factors}

The study found that $6.9 \%$ of boys and $3.8 \%$ of girls reported sexual intercourse in the past 12 months (Table 2). Furthermore, among those who engaged in sexual intercourse, $72.7 \%$ of boys and $90.3 \%$ of girls had their first sexual experience before reaching 15 years of age, and around $60 \%$ of sexually active boys and girls had more than 1 sexual partner (Table 3). As is also shown in Table 3, more junior secondary students (5.8\%) had sexual intercourse than high school students (3.7\%).
Table 2. Background characteristics of school-aged adolescents, GSHS 2015, Indonesia

\begin{tabular}{|c|c|c|c|}
\hline Characteristics & Boys & Girls & Total \\
\hline \multicolumn{4}{|l|}{ Sexual behaviour } \\
\hline Sexual intercourse & $290(6.9)$ & $210(3.8)$ & $500(5.3)$ \\
\hline \multicolumn{4}{|l|}{ Socio-demographic } \\
\hline Gender & 5090 (45.8) & $6020(54.2)$ & $11110(100)$ \\
\hline \multicolumn{4}{|l|}{ Grade } \\
\hline Junior secondary (7-9) & $3874(79.2)$ & $4163(74.4)$ & $8037(76.8)$ \\
\hline High school (10-12) & $1196(21.8)$ & $1833(25.6)$ & $3029(23.2)$ \\
\hline \multicolumn{4}{|l|}{ Age (y) } \\
\hline$<15$ & 3268 (66.9) & 3834 (68.4) & $7102(67.7)$ \\
\hline$\geq 15$ & $1822(33.1)$ & $2186(31.6)$ & $4008(32.3)$ \\
\hline \multicolumn{4}{|l|}{ Substance use } \\
\hline Current smoking & $1156(23.2)$ & $148(2.4)$ & $1304(12.6)$ \\
\hline Current alcohol drinking & $365(7.3)$ & $104(1.6)$ & $469(4.4)$ \\
\hline Drug use & $166(3.3)$ & $50(0.9)$ & $216(2.1)$ \\
\hline \multicolumn{4}{|l|}{ Mental distress } \\
\hline Loneliness & $268(5.5)$ & 419 (6.8) & $687(6.2)$ \\
\hline Anxiety & $254(5.0)$ & $258(4.2)$ & $512(4.6)$ \\
\hline Suicidal ideation & $215(4.3)$ & $382(5.9)$ & $597(5.1)$ \\
\hline \multicolumn{4}{|l|}{ Protective factors } \\
\hline Truancy & $1265(24.0)$ & $1070(16.4)$ & $2335(20.1)$ \\
\hline Peer support & $1714(34.0)$ & $2556(44.0)$ & $4270(39.1)$ \\
\hline Parental supervision & $2533(50.3)$ & $3583(61.1)$ & $6116(55.9)$ \\
\hline Knowledge of HIV/AIDS & $3514(73.4)$ & $4683(79.3)$ & $8197(76.4)$ \\
\hline Lesson on HIV/AIDS at school & $2559(61.3)$ & $3374(64.7)$ & $5933(63.1)$ \\
\hline $\begin{array}{l}\text { Lesson on HIV/AIDS prevention } \\
\text { at school }\end{array}$ & $2491(60.5)$ & $3376(65.0)$ & $5867(62.9)$ \\
\hline
\end{tabular}

Values are presented as number (\%).

GSHS, Global School-based Health Survey.

Among students in grades 7-9 who had sexual experience, $94.5 \%$ had an early sexual debut ( $<15$ years).

The results of the multiple logistic regression analysis are presented in Table 4. In the bivariate analysis, all variables were significantly associated with sexual intercourse among schoolaged children $(p<0.05)$. However, after adjustment for sociodemographic, substance use, mental distress, and protective variables in the multivariate analysis, the variables that were associated with the outcome were men gender (OR, 1.42; 95\% $\mathrm{Cl}, 1.15$ to 1.75$)$, grade $10-12(\mathrm{OR}, 0.56 ; 95 \% \mathrm{Cl}, 0.43$ to 0.71$)$, current smoking (OR, 1.36; $95 \% \mathrm{Cl}, 1.01$ to 1.83$)$, current alcohol drinking (OR, 2.24; $95 \% \mathrm{Cl}, 1.52$ to 3.31), drug use (OR, 10.17; $95 \% \mathrm{Cl}, 5.20$ to 19.89$)$, suicidal ideation (OR, 2.68; $95 \% \mathrm{Cl}, 1.97$ to 3.65$)$, truancy $(\mathrm{OR}, 1.34 ; 95 \% \mathrm{Cl}, 1.07$ to 1.68$)$, peer support $(\mathrm{OR}, 0.78 ; 95 \% \mathrm{Cl}, 0.63$ to 0.97$)$, and parental supervision (OR, $0.66 ; 95 \% \mathrm{Cl}, 0.54$ to 0.80 ). 
Table 3. Proportion of sexual behaviour among adolescents, by age and school grade GSHS 2015, Indonesia

\begin{tabular}{|c|c|c|c|c|c|c|c|c|c|c|}
\hline \multirow{2}{*}{ Characteristics } & \multicolumn{2}{|c|}{ Sexual intercourse } & \multicolumn{6}{|c|}{ Age at first sex $(y)^{1}$} & \multicolumn{2}{|c|}{ No. of sexual partners } \\
\hline & No & Yes & $\leq 11$ & 12 & 13 & 14 & 15 & $\geq 16$ & 1 person & $>1$ person \\
\hline \multicolumn{11}{|l|}{ Gender (\%) } \\
\hline Men & 93.1 & 6.9 & 32.5 & 18.2 & 10.4 & 11.7 & 11.7 & 15.6 & 39.0 & 57.5 \\
\hline \multicolumn{11}{|l|}{ Grade (\%) } \\
\hline
\end{tabular}

GSHS, Global School-based Health Survey.

${ }^{1}$ Among students who ever had sexual intercourse.

Table 4. Multiple logistic regression of sexual intercourse in relation to socio-demographic, substance use and other protective variables, GSHS 2015, Indonesia

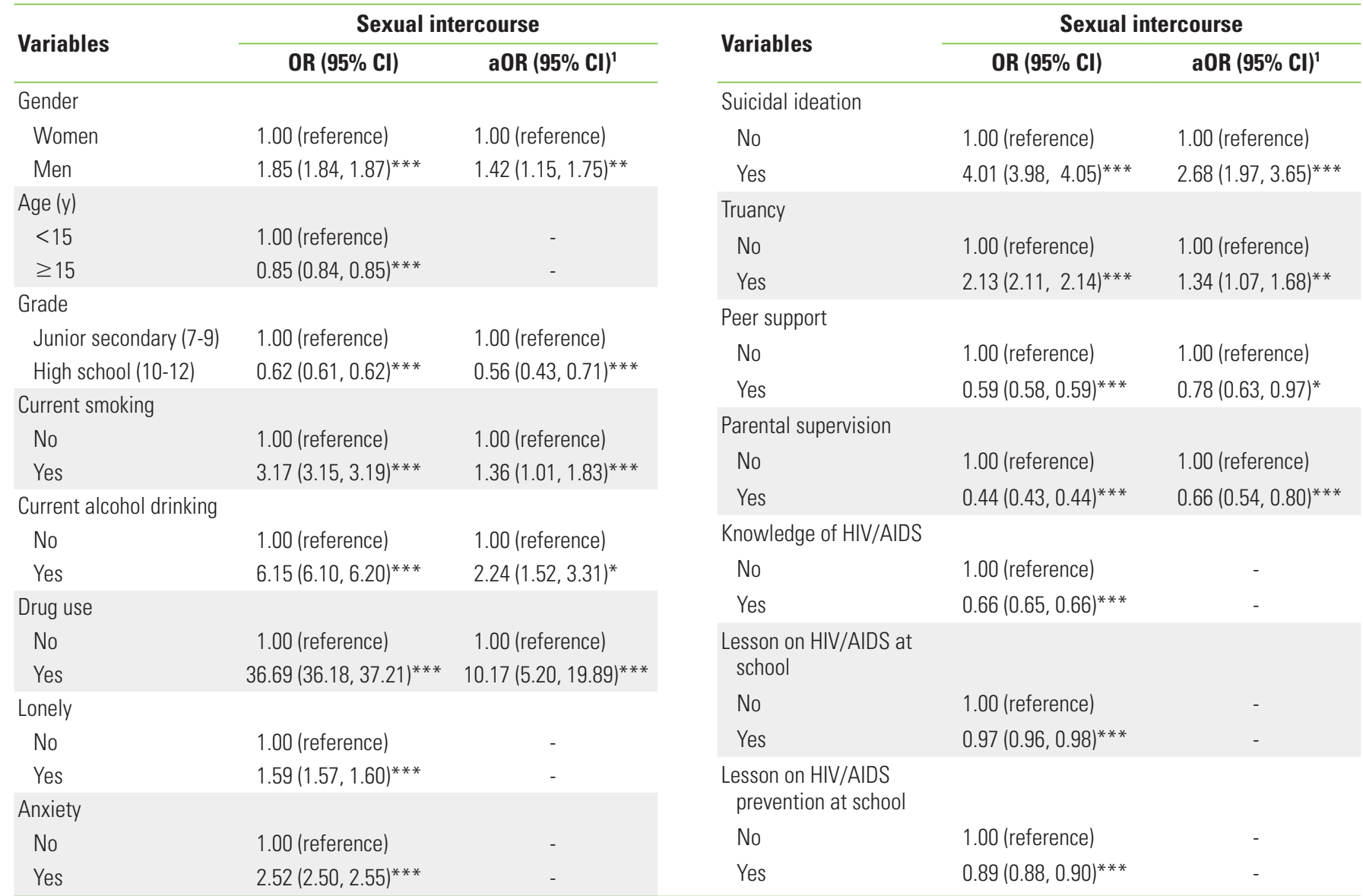

GSHS, Global School-based Health Survey; OR, odds ratio; Cl, confidence interval; aOR, adjusted odds ratio.

${ }^{1}$ Adjusted for all variables; Smoking was considered as potential confounder, so it retained from the model; The Hosmer-Lemeshow test ( $\left.p=0.52\right)$ indicated a good fit to the data.

${ }^{*} p<0.05,{ }^{* *} p<0.01,{ }^{* * *} p<0.001$.

\section{DISCUSSION}

This paper reports that more adolescent boys (6.9\%) in Indonesia than girls (3.8\%) had engaged in sexual intercourse.
Similar findings were found in some previous GSHS studies [9$11,15]$. The majority of both man and woman students who ever had sexual intercourse had their sexual debut before the age of 15 ( $90.3 \%$ for girls and $72.7 \%$ for boys). The lower debut 
age among girls could be explained by the fact that girls tend to have an earlier onset of puberty than boys, and this is positively correlated with an early sexual debut [16]. These results, however, should be interpreted with caution since the majority (67.7\%) of participants were under the age of 15 years. Our findings also found that more girls than boys reported having more than 1 sexual partner, which contradicts the findings of previous studies in the Pacific Islands and sub-Saharan Africa $[9,11,15]$. The risk of having multiple sexual partners among adolescent girls is known to be associated with several contextual factors, including family structure and household economic status, which were not investigated in the survey [17].

The current study further demonstrated that gender, school grade, substance use (tobacco, alcohol, and drugs), suicidal ideation, school truancy, peer support, and parental supervision were associated with sexual intercourse in the past 12 months. Boys were more likely to have engaged in sexual intercourse than girls. It has been argued that boys and girls have different experiences of puberty and sexual behaviours [18]. Boys are more likely to have positive expectations about sex, whilst girls seem to have emotional reasons for having sex, which are mostly related to other needs such as the need for love, self-esteem, and self-ascertainment [19].

These differences are not merely due to different psychological or biological characteristics of boys and girls. Previous literature suggests that race, ethnicity, and sexual preference also shape adolescents' experiences of puberty and first sexual debut [18]. In addition, sociocultural and environmental factors, such as family upbringing, have a strong influence on adolescents' perceptions of sexuality and their sexual behaviour [20]. Physical and biological changes during puberty make boys look older, more masculine, and more independent to parents; thus, boys are granted more recognition of their selves. For girls, looking older means looking more sexual, to which parents often respond by implementing greater restrictions, rather than by enabling greater independence [18].

Substance use (tobacco, drugs, and alcohol) was associated with an increased likelihood of sexual intercourse in this study. Similar findings were reported in the previous GSHS studies in the Pacific Islands, Brunei Darussalam, and Namibia $[9,11,12]$. The majority of teenagers reporting early sexual behaviour also reported using alcohol and drugs before sex [21,22]. Alcohol alone has been reported to increase the desire to have sex and to initiate or participate in sex [22-24]. The use of intravenous drugs or other illicit substances has also been reported to increase cognitive inhibition [25] and poor behavioural judgment [26]. Several illicit drugs, such as opium, produce intense feelings of pleasure, which could directly stimulate feelings of sexual desire and pleasure [24].

Current smoking was also significantly associated with early sexual debut among school-aged adolescents. Recent evidence suggests that individuals who initiate smoking at a relatively early age tend to engage in unprotected sex under the influence of alcohol or drugs [27]. Although the causal nature of this relationship remains unclear [28], it is important to point out that adolescents who reported having ever smoked were identified as much more likely to engage in sexual intercourse. In Indonesia, people start smoking at a relatively young age. The 2014 Global Youth Tobacco Survey found that of $43.2 \%$ of students who have ever smoked a cigarette reported that they started smoking at 12-13 years of age [29]. Therefore it is necessary to implement smoking behaviour control strategies through health education on the dangers of smoking that starts at a very young age, although such policies are apparently insufficient to curb the rate of smoking, especially among teenagers [30].

Another distinctive finding of this study was the positive association between suicidal ideation and sexual intercourse. Although this result is consistent with previous studies among school-going adolescents [11], the nature of the relationship remains unclear. A study in Sweden found that perceived poorer health and mental well-being was more prominent among girls with early sexual debut (at the age of 14 or younger). The increased probability of sexual intercourse in relation to poor mental health among adolescents could be explained based on proposals made in several studies [11]. For instance, the concept of self-efficacy in Bandura's social cognitive theory suggests that people who are depressed have less capacity to take control over their lives, including areas pertaining to sexual behaviour [11,31]. Hence, adolescents who have higher sexual self-efficacy may exhibit less risky sexual behaviour.

Regarding protective factors, our study found that having close friends and/or parental or guardian supervision decreased the likelihood of adolescents being sexually active, which is consistent with previous GSHS study findings [9,32]. The social environment provides meaningful relationships, encourages self-expression, and provides structure that may help prevent adolescents from initiating sex at a young age [18]. Parents are known to be health-promoting socialisation agents for information about norms and behaviours, who are likely to encour- 
age their children to delay the onset of sexual intercourse [33]. Parents and schools may have positive impacts on adolescent's sexual cognition to postpone sexual intercourse, while peers and mass media provide information that might accelerate adolescents' sexual activity [34]. Peer relationships have the potential to promote risky sexual behaviour, as peers are a source of emotional support among teenagers [35].

In an effort to delay the initiation of sexual intercourse and prevent sexually transmitted infections, school-aged adolescents should be provided with sexual health education and be encouraged through positive attitudes regarding gender and adolescent reproductive health (ARH) norms during puberty based on the social and cultural context of Indonesia. Since sexuality remains a taboo and sensitive subject in many areas of Indonesia, it is rarely discussed by adolescents explicitly with their parents [36]. This leads parents to be a bit conservative when explaining information related to sexuality to their children. Similar to parents, school teachers often neglect that teaching students about sexuality must be done with a gender-neutral approach. Indeed, ARH is only addressed to a limited degree [37].

Culturally appropriate and evidence-based education on sexuality and ARH is therefore important to help adolescents be well-informed about healthy relationships and take responsibility for their SRH. To date, the implementation of ARH education in schools has been associated with health movements in schools (Usaha Kesehatan Sekolah) through counselling, periodic health check-ups, and immunisations [38]. It is encouraging to equip the curriculum with the topic of sex education, with the aim of enabling students to obtain accurate information for developing their own personal attitudes related to sexuality. In addition, school-based strategies should also address other risky behaviours, such as smoking and other substance use.

\section{Strengths and limitations}

There are several limitations to this study. As adolescents who did not attend school were not included, the findings may not be representative of all adolescents. Also, as the survey was cross-sectional, no causal interpretations can be made. The survey used in this study relies mainly on self-reports of sexual behaviour, some of which may be misreported due to shame and taboo concerning early sexual debut. We also used proxy measures for depression, anxiety, and suicide, which are quite limited in their use as quantitative measures of mental health.
Nevertheless, this study may contribute to the following: (1) the identification of the correlations of sexual behaviour with smoking, alcohol consumption, suicide, and truancy among students in Indonesia; (2) the development of specific insights on understanding unhealthy behaviours among adolescents in the Indonesian context, which may require further action by the authorities for both education and health sectors; (3) the provision of recommendation on strategies to address risky behaviours among adolescents in Indonesia.

Our study found a low prevalence of sexual intercourse among in-school adolescents in Indonesia. The factors associated with sexual activity were gender, school grade, substance use (tobacco, alcohol, and drugs), suicidal ideation, school truancy, peer support, and parental supervision. Our findings suggest that there is an urgent need to review the current school health policies and curriculum. Strategies for changing unhealthy behaviours strategies should include educational programs on school-based comprehensive sexual reproductive health and substance use control. Further research is also needed to examine the social patterns and determinants of engagement in adolescent sexual behaviours. This would provide more insights for points that ARH programs should be emphasised in the context of students in Indonesia.

\section{CONFLICT OF INTEREST}

The authors have no conflicts of interest associated with the material presented in this paper.

\section{FUNDING}

None.

\section{ACKNOWLEDGEMENTS}

The authors wish to express gratitude to the World Health Organization (WHO) and Centres for Disease Control (CDC), Atlanta, Georgia, United States, for financial and technical support for this study, and to the WHO country office in Indonesia for facilitating the data collection. We also thank to the Ministry of Health, and Ministry of Education, who allowed and supported the study to take place. We acknowledge the research collaboration on adolescents' health topic for Indonesia context through the University of New South Wales (UNSW)-Indonesia Seed-Funding Project. Finally, we thank to the students 
who have given generously of their time and participation to the study.

\section{AUTHOR CONTRIBUTIONS}

Conceptualization: AR, IBM, NK. Data curation: AR, NK. Formal analysis: AR. Funding acquisition: None. Methodology: NK, CL. Project administration: NK. Visualization: AR. Writing original draft: AR. Writing - review \& editing: IBM, NK, CL, JFP.

\section{ORCID}

Anissa Rizkianti https://orcid.org/0000-0002-1255-5199 Iram Barida Maisya https://orcid.org/0000-0001-6393-8969 Nunik Kusumawardani https://orcid.org/0000-0002-99505644

Christine Linhart https://orcid.org/0000-0002-8104-2688

Jerico Franciscus Pardosi https://orcid.org/0000-0003-37535669

\section{REFERENCES}

1. UNICF. UNICEF data: monitoring the situation of children and women: Indonesia [cited 2020 Feb 1]. Available from: https:// data.unicef.org/country/idn/.

2. UNICEF. The state of the world's children 2016 statistical tables; 2016 [cited 2020 Feb 1]. Available from: https://data.unicef. org/resources/state-worlds-children-2016-statistical-tables/.

3. Pérez Fuentes MD, Molero Jurado MD, Carrión Martínez JJ, Mercader Rubio I, Gázquez JJ. Sensation-seeking and impulsivity as predictors of reactive and proactive aggression in adolescents. Front Psychol 2016;7:1447.

4. Morris JL, Rushwan H. Adolescent sexual and reproductive health: the global challenges. Int J Gynecol Obstet 2015;131 (Suppl 1):S40-S42.

5. National Population and Family Planning Board (BKKBN), Statistics Indonesia (BPS), Ministry of Health (Kemenkes), ICF. Indonesia Demographic and Health Survey 2017: adolescent reproductive health; 2018 [cited 2020 Sep 11]. Available from: https://dhsprogram.com/pubs/pdf/FR343/FR343.pdf.

6. Violita F, Hadi EN. Determinants of adolescent reproductive health service utilization by senior high school students in Makassar, Indonesia. BMC Public Health 2019;19(1):286.

7. Ministry of Health Indonesia. Brief overview: HIV among adolescent and young key populations (aged 15-19 and 20-24) in
Indonesia; 2015 [cited 2020 Sep 11]. Available from: http:// www.childrenandaids.org/sites/default/files/2018-11/HIV\% 20among\%20adolescent\%20and\%20young\%20key\%20populations\%20in\%20Indonesia.pdf.

8. Ocviyanti D, Dorothea M. Aborsi di Indonesia. J Indon Med Assoc 2018;68(6):213-215 (Indonesian).

9. Peltzer K, Pengpid S. Risk and protective factors affecting sexual risk behavior among school-aged adolescents in Fiji, Kiribati, Samoa, and Vanuatu. Asia Pac J Public Health 2016;28(5): 404-415.

10. Peltzer K, Pengpid S. Early sexual debut and associated factors among in-school adolescents in six Caribbean countries. West Indian Med J 2015;64(4):351-356.

11. Seidu AA, Ahinkorah BO, Ameyaw EK, Darteh EK, Budu E, Iddrisu $\mathrm{H}$, et al. Risky sexual behaviours among school-aged adolescents in Namibia: secondary data analyses of the 2013 Global school-based health survey. Z Gesundh Wiss 2019. doi: https://doi.org/10.1007/s10389-019-01140-x.

12. Pengpid S, Peltzer K. Sexual behaviour and its correlates among adolescents in Brunei Darussalam. Int J Adolesc Med Health 2018;20180028.

13. Leerlooijer JN, Ruiter RA, Damayanti R, Rijsdijk LE, Eiling E, Bos $A E$, et al. Psychosocial correlates of the motivation to abstain from sexual intercourse among Indonesian adolescents. Trop Med Int Health 2014;19(1):74-82.

14. Wijaya MK, Giri MK, Wahyuni NP, Setiawan KH. Premarital sex behaviors of teenagers: a case in Bali, Indonesia. Int J Health Sci 2018;2(3):11-21.

15. Shayo FK, Kalomo MH. Prevalence and correlates of sexual intercourse among sexually active in-school adolescents: an analysis of five sub-Sahara African countries for the adolescent's sexual health policy implications. BMC Public Health 2019;19(1):1285.

16. Kastbom ÅA, Sydsjö G, Bladh M, Priebe G, Svedin CG. Sexual debut before the age of 14 leads to poorer psychosocial health and risky behaviour in later life. Acta Paediatr 2015;104(1):91100.

17. Pilgrim NA, Ahmed S, Gray RH, Sekasanvu J, Lutalo T, Nalugoda $\mathrm{F}$, et al. Multiple sexual partnerships among female adolescents in rural Uganda: the effects of family structure and school attendance. Int J Adolesc Med Health 2015;27(3):319-328.

18. Martin K. Puberty, sexuality and the self: girls and boys at adolescence. Florence: Routledge; 2018, p. 88-89.

19. Tulloch T, Kaufman M. Adolescent sexuality. Pediatr Rev 2013; 34(1):29-38. 
20. HowStuffWorks.Com Contributors. Can adolescent development change according to culture and upbringing?; 2011 [cited 2020 Feb 1]. Available from: https://lifestyle.howstuffworks. com/family/parenting/tweens-teens/adolescent-development-change-according-culture-upbringing.htm.

21. Parkes A, Waylen A, Sayal K, Heron J, Henderson M, Wight D, et al. Which behavioral, emotional and school problems in middle-childhood predict early sexual behavior? J Youth Adolesc 2014;43(4):507-527.

22. Ritchwood TD, Ford H, DeCoster J, Sutton M, Lochman JE. Risky sexual behavior and substance use among adolescents: a meta-analysis. Child Youth Serv Rev 2015;52:74-88.

23. Shashikumar R, Das RC, Prabhu HR, Srivastava K, Bhat PS, Prakash J, et al. A cross-sectional study of factors associated with adolescent sexual activity. Indian J Psychiatry 2012;54(2): 138-143.

24. Nevid JS, Rathus SA, Greene B. Abnormal psychology in a changing world. 8th ed. Boston: Prentice Hall; 2011, p. 145-147.

25. Juárez-Portilla C, Molina-Jiménez T, Morin J, Roldán-Roldán G, Zepeda RC. Influence of drugs on cognitive functions. In: Bernal-Morales B, editor. Health and academic achievement. London: IntechOpen; 2018, p. 59-82.

26. Paquette R, Tanton C, Burns F, Prah P, Shahmanesh M, Field N, et al. Illicit drug use and its association with key sexual risk behaviours and outcomes: findings from Britain's third National Survey of Sexual Attitudes and Lifestyles (Natsal-3). PLoS One 2017;12(5):e0177922.

27. Furlanetto MF, Ghedin DM, Gonçalves TR, Marin AH. Individual and contextual factors associated with sexual initiation among adolescents. Psicol Reflex Crit 2019;32(1):25.

28. Hansen BT, Kjaer SK, Munk C, Tryggvadottir L, Sparén P, Hagerup-Jenssen $\mathrm{M}$, et al. Early smoking initiation, sexual behavior and reproductive health - a large population-based study of Nordic women. Prev Med 2010;51(1):68-72.

29. World Health Organization, Regional Office for South-East Asia. Global Youth Tobacco Survey (GYTS) Indonesia report, 2014 [cited 2020 Sep 11]. Available from: https://apps.who.int/iris/ handle $/ 10665 / 205148 ?$ mode $=$ simple

30. Kumboyono K, Hamid AY, Sahar J, Bardosono S. Community response to the initiation of smoking in Indonesian early adolescents: a qualitative study. Int J Adolesc Youth 2020;25(1): 210-220.

31. Hsu HY, Yu HY, Lou JH, Eng CJ. Relationships among sexual selfconcept and sexual risk cognition toward sexual self-efficacy in adolescents: cause-and-effect model testing. Jpn J Nurs Sci 2015;12(2):124-134.

32. Dittus PJ, Michael SL, Becasen JS, Gloppen KM, McCarthy K, Guilamo-Ramos V. Parental monitoring and its associations with adolescent sexual risk behavior: a meta-analysis. Pediatrics 2015;136(6):e1587-e1599.

33. Okigbo CC, Kabiru CW, Mumah JN, Mojola SA, Beguy D. Influence of parental factors on adolescents' transition to first sexual intercourse in Nairobi, Kenya: a longitudinal study. Reprod Health 2015;12:73.

34. Bingenheimer JB, Asante E, Ahiadeke C. Peer influences on sexual activity among adolescents in Ghana. Stud Fam Plann 2015;46(1):1-19.

35. Forman-Alberti A. Facets of peer relationships and their associations with adolescent risk-taking behavior; 2015 [cited 2020 Feb 1]. Available from: https://www.cyc-net.org/featuresx/ feature-160509.html.

36. Situmorang A. Adolescent reproductive health services at Puskesmas: issues and challenges. J Kependud Indones 2016;6(2):21-32 (Indonesian, author's translation).

37. Safitri S. Applying a sex education programme in elementary schools in Indonesia: theory, application, and best practices. In: Ariyanto AA, Muluk H, Poerwandari EK, Newcombe P, Piercy FP, Suradijono SH, editors. Diversity in unity: perspectives from psychology and behavioral sciences. London: Routledge; 2018, p. 218.

38. Susanto T, Rahmawati I. A community-based friendly health clinic: an initiative adolescent reproductive health project in the rural and urban areas of Indonesia. Int J Nurs Sci 2016;3(4): 371-378. 